Abstracta Iranica Abstracta Iranica

Revue bibliographique pour le domaine irano-aryen

Volume 24 | 2003

Comptes rendus des publications de 2001

\title{
L'Evidence du film, The Evidence of Film, Bardāšt-e film. Yves Gevart éd., 2001, Bruxelles, 96 p. et 12 p. D'iconographie.
}

\section{Agnès Devictor}

\section{(2) OpenEdition}

1 Journals

\section{Édition électronique}

URL : http://journals.openedition.org/abstractairanica/35029

DOI : 10.4000/abstractairanica.35029

ISSN : 1961-960X

Éditeur :

CNRS (UMR 7528 Mondes iraniens et indiens), Éditions de l'IFRI

\section{Édition imprimée}

Date de publication : 15 mai 2003

ISSN : 0240-8910

\section{Référence électronique}

Agnès Devictor, «L'Evidence du film, The Evidence of Film, Bardāšt-e fillm. Yves Gevart éd., 2001,

Bruxelles, 96 p. et 12 p. D'iconographie. », Abstracta Iranica [En ligne], Volume 24 | 2003, document 385, mis en ligne le 05 janvier 2010, consulté le 25 septembre 2020. URL : http://journals.openedition.org/ abstractairanica/35029 ; DOI : https://doi.org/10.4000/abstractairanica.35029

Ce document a été généré automatiquement le 25 septembre 2020.

Tous droits réservés 


\title{
L'Evidence du film, The Evidence of Film, Bardāšt-e film. Yves Gevart éd., 2001, Bruxelles, 96 p. et 12 p. D’iconographie.
}

\author{
Agnès Devictor
}

1 Cet essai trilingue s'articule autour de trois textes: une approche du cinéma de Kiyārostamī par le philosophe Jean-Luc Nancy, un texte sur Et la vie continue [1992], publié dans une première version dans la revue Cinémathèque, et pour clore l'ouvrage, un entretien entre le philosophe et le réalisateur.

2 Ce livre relève d'une démarche originale: donner la parole à un philosophe pour penser le cinéma et plus particulièrement les films réalisés par Kiyārostamī depuis 1992 : l'interrogation portée sur l'œuvre du réalisateur, la "mobilisation du regard» qu'elle exige et la manière dont "un autre monde se donne d'autres formes ». J. L. Nancy définit le cinéma de Kiyārostamī comme "mouvement du réel », "présence » bien plus que représentation. Outre la richesse des deux textes, le dialogue entre le philosophe et le réalisateur développe la pensée très théorique de Kiyārostamī sur le cinéma et les formes esthétiques. C'est ainsi que le réalisateur explique la durée de ses plans par les exigences de la création d'images : semblable en cela à la poésie, le cinéma requiert une ouverture sur l'imagination, une contribution libre du spectateur. «Le poème ne raconte jamais une histoire, il donne une série d'images ». Pour Kiyārostamī, «Il faut envisager un cinéma inachevé et incomplet pour que le spectateur puisse intervenir et combler les vides, les manques. Au lieu de faire un film avec une structure solide et impeccable, il faut affaiblir celle-ci - tout en ayant conscience qu'il ne faut pas faire fuir le spectateur!». Tout au long de cette discussion, Kiyārostamī livre une brillante théorie du cinéma. C'est même bien souvent lui qui ramène le philosophe sur le terrain de la réflexion conceptuelle, démontrant à quel point le cinéma aide à penser. 
INDEX

Thèmes : 17.2. Arts du spectacle

\section{AUTEURS}

AGNÈS DEVICTOR

Paris 